\title{
CARACTERÍSTICAS Y PROPIEDADES FÍSICO-QUÍMICAS DE LA SALIVA: UNA REVISIÓN
}

\author{
${ }^{1}$ Anne Alejandra Hernández Castañeda, ${ }^{2}$ Gloria Cristina Aranzazu Moya \\ ${ }^{1}$ Odontóloga U. Santo Tomás. Joven Investigador Colciencias - U. Santo Tomás, Colombia. \\ ${ }^{2}$ Odontóloga U. Santo Tomás, Especialista en Patología y Medios Diagnósticos U. El Bosque, Docente U. Santo Tomás, Colombia.
}

Autor responsable de correspondencia: Anne Alejandra Hernández Castañeda

Correo electrónico: anne.usta@hotmail.com

\section{RESUMEN}

La saliva es un líquido que humedece la cavidad bucal y es secretado por las glándulas salivales. Dentro de sus propiedades fundamentales se encuentran la protección de la mucosa bucal y dientes, defensa a través de las lisozimas, cooperación en la digestión, regulación del pH por su función de tampón al evitar las lesiones producidas por el exceso de bases y ácidos y la limpieza de la boca a través de los movimientos masticatorios, que se pueden efectuar por la humectación de la saliva. Una disfunción salival como la misma reducción en la cantidad de secreción o los cambios en las concentraciones químicas como parte de las propiedades de la saliva son responsables de una gran cantidad de problemas bucales que pueden tener un impacto directo en el estado general de la salud del paciente. Por lo tanto, es importante conocer tanto las características como las propiedades físico-químicas de la saliva, objetivo de esta revisión. [Hernández AA, Aranzazu GC. Características y propiedades físico-químicas de la saliva: una revisión. Ustasalud 2012; 11: - ]

Palabras clave: Saliva, Glándulas salivales, Acidificación

\section{CHARACTERISTICS AND PHYSICAL CHEMICAL PROPERTIES OF SALIVA: A REVIEW}

\section{ABSTRACT}

Saliva is a liquid secreted by the salivary glands, which moistens the mouth. Among the fundamental properties are protection of the oral mucosa and teeth, defense through lysozyme, cooperation in digestion, regulation of $\mathrm{pH}$ by function buffer, preventing injuries from excess acids and bases, and cleaning of the mouth through chewing movements that can be effected by wetting of the saliva. Salivary dysfunction as the same reduction in the amount of secretion, or changes in chemical concentrations as part of the properties of saliva, is responsible for a large amount of oral and dental problems associated, which have a direct impact on the general health status of the patient. Therefore, it is important to know the characteristics and physicochemical properties of saliva focus of this review.

Key words: Saliva, Salivary glands, Buffers

Recibido para publicación: septiembre 19 de 2012. Aceptado para publicación: diciembre 13 de 2012.

\section{INTRODUCCIÓN}

La saliva es un líquido que humedece la cavidad bucal, es secretada por todas las glándulas salivales ${ }^{1-4}$ más específicamente de las glándulas salivales mayores en el $93 \%$ de su volumen y de las menores en el $7 \%$ restante, las cuales se extienden por todas las regiones de la boca excepto en la encía y en la porción anterior del paladar duro. Es estéril cuando sale de las glándulas salivales, pero deja de serlo inmediatamente cuando se mezcla con el fluido crevicular, restos alimenticios, microorganismos y células descamadas de la mucosa oral. ${ }^{5}$

La saliva se define como una secreción mixta producto de la mezcla de los fluidos provenientes de las glándulas salivales mayores, de las glándulas salivales menores y del fluido crevicular. Contiene agua, mucina, proteínas, sales, enzimas, además de bacterias que normalmente residen en la cavidad bucal, células planas producto de la descamación del epitelio bucal, linfocitos y granulocitos degenerados llamados corpúsculos salivales los cuáles provienen principalmente de las amígdalas. Puede variar la consistencia de muy líquida a viscosa dependiendo de la glándula que la produzca y la excrete dentro de la cavidad oral ${ }^{6,7}$

Las glándulas salivales están formadas por células acinares y ductales, las células acinares de la parótida producen una secreción esencialmente serosa y en ella se sintetiza mayoritariamente la alfa amilasa, esta glándula produce menos calcio que la submandibular. ${ }^{1}$ Las mucinas proceden, sobre todo, de las glándulas submandibular y sublingual y las proteínas ricas en prolina e histatina de la parótida y de la submandibular. Las glándulas salivales menores son esencialmente mucosas. ${ }^{1}$

La secreción diaria oscila entre 500 y $1500 \mathrm{~mL}$ por 
día en un adulto, ${ }^{2}$ con un volumen medio en la boca de $1,1 \mathrm{~mL}$. Su producción está controlada por el sistema nervioso autónomo. En reposo, la secreción oscila entre $0,25 \mathrm{~mL} / \mathrm{min}$ y $0,35 \mathrm{~mL} / \mathrm{min}$ y procede sobre todo de las glándulas submandibulares y sublinguales. Ante estímulos sensitivos, eléctricos o mecánicos, el volumen puede llegar hasta $1,5 \mathrm{~mL} / \mathrm{min}$. El mayor volumen salival se produce antes, durante y después de las comidas, alcanza su pico máximo alrededor del medio día y disminuye de forma muy considerable por la noche, durante el sueño. ${ }^{1} \mathrm{El}$ objetivo de este artículo fue hacer una revisión sobre las características principales y las propiedades físico-químicas de la saliva.

\section{Control de la secreción salival}

La secreción de saliva es un proceso de dos etapas con la secreción inicial de un plasma como fluido primario acuoso por las células acinares y su posterior modificación durante el paso a través del sistema celular ductal impermeable al agua. La secreción es controlada por el sistema nervioso autónomo a través de los sistemas de transducción de señales de estimulación del receptor para el transporte de iones y secreción de proteínas. ${ }^{8,9}$

Los nervios autónomos parasimpáticos y simpáticos regulan la actividad de secreción de la glándula salival. Para el sentido del gusto, estímulos táctiles de la lengua, mucosa oral y estímulos propioceptivos de los músculos masticatorios y del ligamento periodontal, incitan a los núcleos salivales inferiores y superiores dentro del cerebro. Estos núcleos están también influenciados por la corteza cerebral. Estas influencias neurológicas secundan el efecto del estado psicológico en la tasa del flujo salival en reposo. $^{2}$

\section{Composición de la saliva}

La saliva es un fluido biológico tan complejo que es casi imposible reproducirlo a partir de componentes individuales. No es de sorprender que la mayoría de sus componentes sean hidrofilicos; sin embargo, también se presentan algunos componentes hidrofóbicos. El más notable de estos es la enzima lipasa, que se secreta en las glándulas de von Ebner. La lipasa al ser hidrofóbica, puede introducir glóbulos de grasa donde descompone los ácidos grasos. La saliva es un líquido diluido, el cual contiene un $99 \%$ de agua y sirve como solvente para otros componentes que la forman y un $1 \%$ de sólidos disueltos; los cuales pueden ser diferenciados como: componentes orgánicos proteicos, componentes no proteicos y componentes inorgánicos o electrolitos. Contiene también material proveniente del surco gingival, de importancia diagnóstica en lo referente a marcadores de destrucción periodontal. La com- posición salival varía de sitio a sitio dentro de la boca de acuerdo a diferentes situaciones (hora del día, proximidad de las comidas) y sus propiedades son afectadas por el nivel de hidratación y la salud general del individuo $2,9,10$

Puede ser considerada como un filtrado del suero, puesto que se deriva de la sangre. Es decir que el proceso de producción de la saliva está unido al equilibrio del fluido corporal en su totalidad y el flujo de sangre, a través de los tejidos de las glándulas salivales tiene un efecto mayor sobre la producción de la saliva. La saliva parotidea es alta en iones de bicarbonato y amilasa, mientras que la secreción de la glándula submandibular es alta en mucina y calcio; la cual es bastante alta comparada con la del plasma. $^{2}$

\subsection{Componentes orgánicos}

La concentración de proteínas en el fluido salival es alrededor de $200 \mathrm{mg} / \mathrm{mL}$, lo cual representa cerca del 3\% de la concentración de proteínas del plasma. Este porcentaje incluye enzimas, inmunoglobulinas, glicoproteínas y albúminas. ${ }^{9,11}$

\subsection{Componentes inorgánicos}

Se encuentran en forma iónica y no iónica. Se comportan como electrolitos, los más importantes son: sodio, potasio, cloruro y bicarbonato; estos contribuyen con la osmolaridad de la saliva, la cual es la mitad de la del plasma, por lo tanto, la saliva es hipotónica con respecto al plasma., ${ }^{9,12}$ La concentración de los componentes orgánicos e inorgánicos disueltos presenta variaciones en cada individuo según las circunstancias como el flujo salival, el aporte de cada glándula salival, el ritmo circadiano, la dieta, la duración y naturaleza del estímulo, ${ }^{1,9,13}$ las cuales generan diferentes funciones dentro de nuestra cavidad oral, se mantiene una flora bacteriana controlada y un $\mathrm{pH}$ estable. ${ }^{14}$

\section{Proteínas Salivales}

Juegan un rol muy importante en la dinámica de la cavidad bucal puesto que se les atribuyen propiedades antimicrobianas y antifúngicas, participan en la lubricación y mantenimiento de la integridad de la mucosa, contribuyen a aumentar la capacidad buffer y promueven la remineralización, además de participar en los procesos fisiológicos de deglución, digestión, fonación y gusto ${ }^{1}$. La importancia de analizar las variaciones existentes en la composición proteica salival, radica en que éstas moléculas juegan un rol preponderante en el mantenimiento de la salud e integridad tanto de los tejidos dentarios, como de la mucosa oral. ${ }^{15,16}$

La composición molecular de la saliva se puede agrupar en varias familias, constituidas por más 
de un tipo de proteínas, las cuales difieren en su estructura química, propiedades biológicas y funcionales; sirven de protección a los tejidos bucales contra la desecación, las agresiones del medio ambiente, la regulación de los procesos de desmineralización-remineralización, la lubricación de superficies oclusales y el mantenimiento del balance ecológico. Las proteínas también intervienen en un gran número de procesos biológicos, como el soporte celular, la tensión y la flexibilidad de los tejidos, la respuesta inmune y las reacciones enzimáticas. Su especificidad en sus funciones biológicas varía de acuerdo al tipo de moléculas presentes en ella, dentro de éstas están las glucoproteinas ricas en prolina y albúmina encargadas de dar protección, las fosfoproteínas, tirosina, cistatina $S$, PRP's aniónicas, histatinas neutrales que regulan el mantenimiento de la integridad dental, las mucinas y cistatinas, que mantienen la integridad de las mucosas, el factor de crecimiento epidérmico, encargado de la reparación de los tejidos blandos, los bicarbonatos, fosfatos, úrea, péptidos ricos en histidina, aminoácidos que regulan el mantenimiento del $\mathrm{pH}$ y las responsables de la actividad antimicrobiana, como la IgA secretora, las mucinas, la lisozima, las glucoproteínas básicas, la lactoferrina, la peroxidasa y las histatinas. La fructosa y la glucosa; se consideran los más cariogénicos, no sólo porque su metabolismo produce ácidos, sino porque el Streptococcus mutans lo utiliza para adherirse a la capa superficial del diente. ${ }^{17-20}$

El contenido proteico total en saliva humana puede variar según el método de análisis utilizado. ${ }^{17}$ Se calcula que entre $85 \%$ y $90 \%$ de las proteínas encontradas en la saliva son secretadas por células acinares. Las proteínas salivales pueden ser clasificadas en tres grupos: ${ }^{7}$

Proteínas como histatinas y las proteínas ricas en prolina que están presentes sólo en saliva, las cuales, modifican la adherencia, inhiben el crecimiento y la viabilidad bacteriana.

- Las proteínas que están presentes en varios fluidos del cuerpo incluida la saliva, como es la lisozima que rompe el enlace $\mathrm{N}$-acetilglucosamina o $\mathrm{N}$ - acetilmurámico de la pared celular, degrada la pared de las bacterias Gram positivas, forma luego complejos con IgA y con otras proteínas como la Peroxidasa. Las mucinas que otorgan viscosidad a la saliva, forman complejos con las bacterias bucales que bloquean adhesinas evitando así que se unan al epitelio mucoso. Compiten con los receptores presentes en el epitelio al formar complejos con las IgAs y otras proteínas salivales, permitiendo su acción antibacte- riana. Las inmunoglobulinas más importantes que participan en la inmunidad a la caries son las IgA e IgG.

- Las proteínas que no provienen de las glándulas secretorias sino de otras fuentes como el plasma sanguíneo, como la albúmina, se han detectado como un componente menor.?

\subsection{Amilasa}

La función predigestiva de la saliva está mediada por un número de enzimas, incluidas la amilasa, la lipasa, y una gama de proteasas y nucleasas. La amilasa puede descomponer féculas y glicógenos en componentes más pequeños, como las dextrinas límite y la maltosa. Al descomponer carbohidratos complejos, que pueden adherirse a los dientes, la amilasa puede tener un papel protector limitado. ${ }^{2,7,14}$

\subsection{Albúmina}

Es la proteína más abundante en suero del plasma, constituye del 55 al 62\% del total de las proteínas séricas. Las concentraciones de la albúmina en saliva y otras secreciones mucosas reflejan una contribución pasiva de derivados proteínicos del suero, que pueden ser originados por la inflamación del epitelio. Esta proteína en pacientes sanos se encuentra en pequeñas cantidades pero en personas con gingivitis y periodontitis se han encontrado cantidades significativamente mayores. ${ }^{7,14}$

\subsection{Mucina}

Las mucinas por interacciones hidrofilicas, enlazan agua que es esencial para mantener la hidratación de la mucosa oral, las mucinas de bajo peso molecular ayudan a limpiar la cavidad oral de las bacterias al unirse con microorganismos y al aglutinarlos; estas mucinas tienden a disminuir con la edad. La interacción entre el agua y las mucinas tiene un gran efecto sobre la viscosidad de la saliva; la cantidad de agua es inversamente proporcional a la concentración de mucinas, que genera una consistencia salival más viscosa y pegajosa especialmente cuando existe una reducción de agua, resultando en un aumento relativo de la concentración de mucinas. Además de lubricar la cavidad oral y prevenir la deshidratación de la mucosa oral, las mucinas salivales cumplen otras funciones. Protegen la superficie mucosa y limitan el alcance de abrasión de las células epiteliales de la mucosa oral causada por una función masticatoria normal. Una capa uniforme de mucinas con una concentración adecuada da también una superficie más lisa para el flujo de aire al hablar. ${ }^{1}$

Las mucinas forman geles viscosos y elásticos hidrofilicos, que funcionan como barreras protecto- 
ras del epitelio subyacente al daño mecánico y previenen la entrada de agentes nocivos como virus y bacterias. También se considera componente de la película adquirida salival. ${ }^{21,22}$ Sin embargo el papel más importante de las mucinas salivales está en su habilidad de modular la colonización oral por una variedad grande de microorganismos. En saliva, las mucinas pueden unirse a adhesinas específicas en la bacteria para causar aglutinación y agregación de ella, son barridas por el lavado continuo de la cavidad oral. La película adquirida puede facilitar la adhesión bacteriana sobre la superficie del diente y sobre otras bacterias de la placa dental. ${ }^{23}$

\subsection{Prolina}

Se encuentran entre los primeros constituyentes de la película de proteínas salivales, que se deposita sobre la superficie del diente denominada película adquirida. Pueden ser ácidas o básicas. Las proteínas ricas en prolina ácidas constituyen de $25-30 \%$ de todas las proteínas de la saliva. Poseen un dominio N-terminal de 30 aminoácidos que se adhiere fuertemente al esmalte dentario, lo cual transmite un cambio conformacional que expone un sitio de unión para las bacterias dentro del dominio C-terminal. Así, promueven la colonización bacteriana de la superficie del diente, durante la formación de la placa dental. Sus grupos ácidos se cargan negativamente y se unen a iones $\mathrm{Ca}^{2+}$ libres, lo que promueve la remineralización del tejido dentario. Las proteínas ricas en prolina se unen a la superficie de los cristales de fosfato de calcio para impedir su crecimiento. Esta proteína une una considerable porción del calcio en la saliva que ayuda a mantener su proporción correcta de calcio-fosfato iónico. ${ }^{2,22}$

\subsection{Lactoferrina}

Es una metaloproteína con la propiedad de unirse al hierro. Además de hallarse en la saliva, se encuentra presente en las lágrimas y la leche. Se creía que su actividad bacteriostática dependía únicamente de su capacidad de eliminar del medio, el hierro necesario para el metabolismo de los microorganismos. Sin embargo, se ha descubierto que posee un dominio antimicrobiano escondido, que se libera de la molécula por la acción de enzimas proteolíticas digestivas. Por ello, se cree que este dominio bactericida se libera durante la digestión de la lactoferrina en el tracto gastrointestinal, lo que puede relacionarse con el papel protector de las proteínas salivales más allá de la cavidad bucal. Se sabe que la lactoferrina es una proteína multifuncional con actividades bactericida, bacteriostática, fungicida y virucida, además de su función moduladora de la respuesta inflamatoria. Esto ha promovido la evaluación de composiciones que la contienen con el fin de mantener la salud bucal. ${ }^{22}$

\section{Funciones de la saliva}

Las funciones de la saliva son principalmente ablandar y humedecer los alimentos para facilitar la digestión y humectar la mucosa oral; además la composición de la saliva misma es un coadyuvante para realizar la excreción de elementos desechables y la regulación de la pérdida o la retención de agua., 14

\subsection{Lubricación}

Además del agua, la presencia de la mucina y de glicoproteínas ricas en prolina, contribuyen con las propiedades lubricantes. La saliva es una cubierta que lubrica y protege los tejidos orales contra los agentes irritantes. Esto se produce debido a las mucinas que son responsables de la lubricación, la protección contra la deshidratación y el mantenimiento de viscoelasticidad salival. También modulan selectivamente la adhesión de los microorganismos a las superficies de los tejidos orales, lo que contribuye al control de la colonización de bacterias y hongos. Además, protegen estos tejidos contra los ataques por microorganismos proteolíticos. La masticación, el habla y la deglución son ayudados por los efectos lubricantes de estas proteínas. Este líquido facilita la formación del bolo alimenticio por su capacidad humectante que transforma los alimentos en una masa semisólida o líquida para que puedan ser deglutidos con facilidad además de permitir la sensación del gusto. ${ }^{9,24}$

\subsection{Capacidad amortiguadora o buffer}

La concentración de iones bicarbonato en la saliva en reposo es menor que en saliva estimulada, al aumentar la concentración de bicarbonato, también se incrementa el $\mathrm{pH}$ y la capacidad amortiguadora de la saliva. Este es un punto clave para interpretar las pruebas de diagnóstico salival. Debido a las variaciones diurnas en la proporción del flujo en reposo, se presentan variaciones correspondientes en los niveles de bicarbonato y, por ende, en el pH y la capacidad amortiguadora. $\mathrm{El} \mathrm{pH}$ en reposo será más bajo al dormir e inmediatamente al despertar. Luego aumenta durante las horas en que se está despierto. ${ }^{2}$ La función amortiguadora de la saliva se debe principalmente a la presencia del bicarbonato ya que la influencia del fosfato es menos extensa.

La capacidad amortiguadora es la habilidad de la saliva para contrarrestar los cambios de $\mathrm{pH}$, es decir, ayuda a proteger los tejidos bucales contra la acción de los ácidos provenientes de la comida o de la placa dental, por lo tanto, puede reducir el potencial cariogénico del ambiente. Los amortiguadores funcionan convirtiendo una solución más débilmente 
ionizada, es decir que libere pocos $\mathrm{H}^{+}$ó $\mathrm{OH}^{-}$. El principal amortiguador de la saliva es el bicarbonato, cuya concentración varía de acuerdo al flujo salival y este mismo es utilizado para la valoración de riesgo de caries; el fosfato y las proteínas también actúan como amortiguadores salivales. ${ }^{4,9,25}$

Es importante destacar el espesor de la biopelícula y el número de bacterias presentes que determinan la eficacia de los tampones salivales; además los residuos cargados negativamente en las proteínas salivales funcionan como amortiguadores. La sialina, un péptido salival, juega un papel importante en el aumento del $\mathrm{pH}$ después de la exposición a los hidratos de carbono fermentables. La úrea es otro tampón presente en el fluido salival total, que es un producto de aminoácidos y el catabolismo de proteínas que causan un rápido aumento en el $\mathrm{pH}$ de la biopelícula mediante la liberación de amoniaco y dióxido de carbono cuando se hidroliza por ureasas bacterianas. ${ }^{7,24,26}$

El buffer ácido carbónico/bicarbonato ejerce su acción sobre todo cuando aumenta el flujo salival estimulado. El buffer fosfato, juega un papel fundamental en situaciones de flujo salival bajo, por encima de un pH de 6 la saliva está sobresaturada de fosfato con respecto a la hidroxiapatita (HA), cuando el $\mathrm{pH}$ se ve disminuido por debajo del $\mathrm{pH}$ crítico $(5,5)$, la HA comienza a disolverse, y los fosfatos liberados tratan de restablecer el equilibrio perdido, lo que dependerá en último término del contenido de iones de fosfato y calcio del medio circundante. Algunas proteínas como las histatinas o la sialina, así como algunos productos alcalinos generados por la actividad metabólica de las bacterias sobre los aminoácidos, péptidos, proteínas y úrea también son importantes en el control del pH 1,7,27, 28,

\subsection{Participación en la formación de la película adquirida}

Por la presencia de proteínas ricas en prolina; la capa de saliva sobre los dientes y la mucosa pueden crear superficies cargadas e influenciar las uniones microbianas, además de crear una capa de lubricación de protección contra el exceso de humedad, la penetración de ácidos y una débil barrera a la salida de minerales..$^{9,11}$

\subsection{Acción antibacteriana de la saliva}

El tener presente numerosos sistemas antimicrobianos ayuda a controlar la flora bacteriana y la protección de los tejidos bucales, fundamentalmente en el control de la caries dental. ${ }^{7}$ Las IgA actúan como anticuerpos salivales, cuya función es participar en la agregación bacteriana y prevenir su adhesión a los tejidos duros y blandos de la cavidad bucal. La IgG y otras inmunoglobulinas derivadas del surco gingival están también presentes en saliva, sin embargo, es poca la fijación que existe para ésta. ${ }^{2}$ La agregación bacteriana también puede suceder por la interacción entre glicoproteínas, mucosas y las adhesinas que son las moléculas receptoras de la superficie bacteriana. Hay proteínas como las histatinas que son un compuesto de sustancias antimicóticas. Además, se debe tomar en cuenta la lucha que mantienen entre ellas para poder sobrevivir en el medio bucal, por lo que el producto del metabolismo de alguna especie bacteriana puede ser fatal para otra. ${ }^{7,9,11,24}$

\subsection{Aclaramiento salival: lavado y eliminación}

El aclaramiento salival se define como la eliminación de una sustancia presente en la saliva en un tiempo determinado. Este es uno de los roles más importantes de la saliva, ya que diluye los substratos bacterianos y azúcares ingeridos. Se encuentra estrechamente vinculado a la tasa de flujo salival; ya que una tasa de flujo salival disminuida trae como consecuencia que la capacidad de lavado o aclaración de los azúcares en saliva sea menor, aumentando la presencia de lesiones cariosas, lo que es más evidente en la vejez. ${ }^{9} \mathrm{El}$ aclaramiento salival es más rápido en unas zonas de la boca que en otras, los lugares más cercanos a la salida de los conductos de las glándulas salivales mayores muestran un rápido aclaramiento o lavado salival y un menor desarrollo de caries que en otras áreas. ${ }^{7,11,24}$

\subsection{Remineralización}

La saliva juega un papel fundamental en el mantenimiento de la integridad físico-químico del esmalte de los dientes por la modulación y la remineralización. ${ }^{24}$ Cuando los dientes hacen erupción, la saliva proporciona los minerales necesarios para que el diente pueda completar su maduración, haciendo que la superficie dentaria sea más dura y menos permeable al medio bucal., 24,29

Los factores que influyen en la remineralización de la hidroxiapatita de los dientes están íntimamente ligados al $\mathrm{pH}$ y a la súper saturación de iones de calcio y de fosfato en la saliva con respecto al diente; esto contribuye al desarrollo de los cristales de hidroxiapatita en la fase de remineralización de los tejidos duros durante el proceso carioso. ${ }^{7,11} \mathrm{La}$ presencia de fluoruro en la saliva, incluso a niveles fisiológicamente bajos, es decisivo para la estabilidad de los minerales dentales. Su concentración en la saliva total se relaciona con su consumo. Es dependiente del fluoruro en el medio ambiente, especialmente en el agua potable. Otras fuentes 
también son importantes, tales como dentífricos y otros productos utilizados en la prevención de caries. La presencia de iones fluoruro en la fase líquida reduce la pérdida de mineral durante una disminución de $\mathrm{pH}$, ya que estos iones disminuyen la solubilidad de la hidroxiapatita dental, por lo que es más resistente a la desmineralización. También se ha demostrado que el fluoruro reduce la producción de ácidos en la biopelícula. ${ }^{24}$

\subsection{Función digestiva}

La saliva es responsable de la digestión inicial del almidón que favorece la formación del bolo alimenticio. Esta acción se produce principalmente por la presencia de la enzima digestiva $\alpha$-amilasa. Su función biológica es dividir el almidón en maltosa, maltotriosa y dextrinas. Esta enzima se considera que es un buen indicador de que funcionen correctamente las glándulas salivales. La mayor parte de esta enzima (80\%) se sintetiza en las parótidas y el resto en las glándulas submandibulares. Su acción se inactiva en las porciones de ácido del tracto gastrointestinal y, por lo tanto, se limita a la boca. ${ }^{24}$

\subsection{Reparación del tejido}

Una función que se atribuye a la saliva es la reparación de tejidos; principalmente en el tiempo de sangrado, ya que en los tejidos orales parece ser más corto que otros tejidos. Cuando la saliva se mezcla experimentalmente con la sangre, el tiempo de coagulación se puede acelerar en gran medida. Algunos estudios experimentales en ratones han demostrado una cicatrización de la herida más rápida en presencia de la saliva debido al factor de crecimiento epidérmico que contiene, el cual es producido por las glándulas submandibulares. ${ }^{24}$

\section{Propiedades de la saliva}

\subsection{Protección frente a la caries dental}

El papel de la saliva en la protección frente a la caries dental se puede concretar en cuatro aspectos: dilución y eliminación de los azúcares y otros componentes, capacidad tampón, equilibrio desmineralización-remineralización y acción anti-microbiana. Una de las funciones más importantes de la saliva es la eliminación de los microorganismos y de los componentes de la dieta en la boca. Tras la ingesta de azúcares hay un pequeño volumen en saliva, el azúcar se diluye en este pequeño volumen hasta alcanzar una alta concentración, ellos estimulan la secreción salival al aumentar así mismo el flujo; el alimento se traga y algo de azúcar queda en la boca que es diluido progresivamente gracias a la saliva que se secretan. Por tanto, un alto volumen de saliva en reposo aumentará la velocidad de eliminación de los azúcares, lo que explica el incremento del riesgo de caries en los pacientes que tienen un flujo salival no estimulado bajo. En el equilibrio dinámico del proceso de la caries la sobresaturación de la saliva proporciona una barrera a la desmineralización y un equilibrio de la balanza hacia la remineralización, dicho equilibrio se ve favorecido por la presencia de flúor. ${ }^{1,30,31}$

La caries dental es una enfermedad que tiene inicio incluso antes del desarrollo de la lesión clínica; su presencia proviene de una etiología multifactorial en la cual interviene la saliva, los hábitos alimenticios, especialmente aquella dieta rica en carbohidratos y sacarosa, además de la superficie dentaria y los microorganismos de la placa bacteriana. La variabilidad en el riesgo de caries dental se relaciona además con la condición física y la habilidad para un buen mantenimiento de la higiene y eliminación de factores predisponentes que se hacen aún más precarios en los adultos mayores, por su condición natural y los medicamentos que consumen que podrían alterar las características naturales de la saliva y, a su vez, el estado dental. ${ }^{1,3,4,32}$

\subsection{Participación de la saliva en la formación de la placa bacteriana}

La película adquirida es una membrana proteinosa y se origina por la absorción de varias proteínas salivales sobre la superficie del esmalte, además de fluido crevicular y productos bacterianos. ${ }^{23} \mathrm{La}$ primera fase en la formación de la placa bacteriana es la formación de la película adquirida, que ocurre a los pocos minutos de haber realizado el cepillado dental, ésta se define como una capa acelular formada por proteínas salivales y otras macromoléculas y constituye la base para una primera colonización de microorganismos, la cual bajo determinadas condiciones se transforma en placa dental; la película adquirida constituye una protección frente a la atrición y abrasión dental. La placa aumenta de espesor y en las zonas más profundas comienzan a predominar los microorganismos anaerobios. Transcurrido el tiempo se forma la placa madura, en cuyas zonas más profundas escasean el oxígeno y los nutrientes y aumenta el acúmulo de productos de desecho, poniéndose en riesgo el número de células viables, pero aun así conserva cierta estabilidad en su composición; esta placa puede mineralizarse y formar el cálculo. La actividad de las proteasas en saliva está íntimamente relacionada con los índices de cálculo, así mismo, la alta concentración de urea en la placa favorece la deposición de calcio y fósforo en la misma; sobre esta placa calcificada puede volver a iniciarse procesos de adherencia bacteriana y proteolítica lo que incrementará su espesor. ${ }^{1}$ 


\subsection{Propiedades reológicas de la saliva}

La saliva humana posee varias propiedades reológicas, entre las que se encuentran viscosidad, elasticidad y adhesividad, debidas a las características únicas químicas y estructurales de las mucinas. La acción lubricante de la saliva es fundamental para la salud bucal. Facilita los movimientos de la lengua y de los labios al comer y es importante para articular las palabras con claridad. La eficacia de la saliva como lubricante dependerá de su viscosidad. ${ }^{33,34}$ varios investigadores, concluyeron que la saliva parotídea es menos viscosa y elástica, además de que la eficacia de la saliva como lubricante depende de su viscosidad y el cambio de la viscosidad con la tasa de desplazamiento. ${ }^{33,35}$ Además de lo anterior es interesante cómo la viscosidad de la saliva varía significativamente con las horas del día, la posible explicación a esta variación es la fluctuación de la composición salival, ya que se ha asumido que la viscosidad como propiedad reológica de la saliva humana está determinada por las glicoproteínas salivales, principalmente las mucinas de alto peso molecular. Las diferencias de viscoelasticidad entre la saliva sublingual y submandibular, obedecen a las especies de mucina presentes en cada secreción y no a las diferencias en su concentración. Pareciera que las mucinas sublinguales poseen mayor elasticidad que las submaxilares y palatinas; por otra parte, las mucinas salivales, que se cree poseen propiedades de lubricación, son secretadas principalmente por las glándulas palatinas, submaxilares y sublinguales. Esto le da mayor apoyo a la teoría que asocia las glicoproteínas salivales a la viscosidad. ${ }^{33,36}$

\subsection{Propiedades tribológicas}

Es la ciencia que estudia la fricción, el desgaste y la lubricación que tienen lugar durante el contacto entre superficies sólidas en movimiento. ${ }^{37,38}$ La presencia de la saliva puede ayudar a disminuir el desgaste dentario al reducir la fricción de la mucosa oral y las superficies linguales contra las estructuras dentales. ${ }^{33} \mathrm{El}$ desgaste dental es un término compuesto usado para englobar la pérdida de superficie dental no cariogénica debido a la atrición, abrasión y erosión; recientemente se ha sugerido que la terminología debería actualizarse y sustituirse por "tribología dental" para armonizar la profesión odontológica con el cuerpo de conocimiento científico de fricción, lubricación y desgaste (tribología). Cabe tener esto en cuenta, dado que los procesos de desgaste individuales, la atrición, abrasión y erosión son peculiares para la odontología y en tribología, tienen escaso o ningún significado y en el caso de la erosión, son descriptivamente incorrectos. Así pues, en tribología, la atrición es el desgaste de dos cuerpos, la abrasión el desgaste de tres cuerpos y la erosión es el desgaste físico-químico. ${ }^{37,38,39}$

\section{Masticación y salivación}

Diversos estudios indican que el aumento de la masticación puede aumentar la producción de saliva, mientras que las reducciones en el esfuerzo masticatorio tienen el efecto contrario. El uso de goma de mascar sin azúcar para mejorar la remineralización por la estimulación del flujo salival es ahora una terapia preventiva aceptada y ha tenido éxito en el mercado. ${ }^{8}$ La masticación estimula el flujo salival, y por ende, aumenta sus propiedades protectoras. Durante la masticación, la tasa del flujo llega a su tope máximo durante el primer minuto. Más allá de este punto, se puede mantener una tasa alta de flujo a través de masticación continua. Sorprendentemente, la tasa del flujo no aumenta dramáticamente por una masticación más veloz: con una tasa del flujo similar sobre frecuencias de masticación que varían entre 35 y 130 acciones masticadoras por minuto, se presenta una tasa del flujo similar, Debido a que un hábito regular de masticación, causa un aumento prolongado en la tasa del flujo salival no estimulado. $^{2}$

\section{La saliva y la enfermedad periodontal}

Ya que la lactoferrina es el componente principal de los gránulos de los neutrófilos y está presente en la saliva y en el fluido gingival crevicular, su interacción con los organismos periodontopatógenos puede ser un elemento importante para la defensa del hospedero contra la enfermedad periodontal, por esta razón se ha estudiado su capacidad citotóxica sobre algunos microorganismos en la que se reportó actividad sobre Aggregatibactes actinomycetemcomitans, Porphyromonas gingivalis, Prevotella intermedia y Prevotella nigrescens en concentraciones fisiológicas en el ambiente secretor de la cavidad oral. ${ }^{40} \mathrm{La}$ respuesta del organismo a la enfermedad periodontal, incluye la producción de algunas enzimas, que son liberadas por las células estromales, epiteliales y por las mismas bacterias. El análisis de estas enzimas en la secreción salival así como en el fluido crevicular, puede contribuir a clarificar la patogénesis y mejorar el diagnóstico precoz de la enfermedad periodontal. Desde este punto de vista, el papel más importante se centra en las enzimas generadas por la destrucción de los tejidos periodontales, como son: elastasa, colagenasa, gelatinasa y proteinasa. ${ }^{41}$

Algunas enzimas intracelulares incrementan su liberación en pacientes con enfermedad periodontal, procedentes de las células periodontales dañadas, y pueden localizarse en la saliva, el líquido crevicular y en las zonas limítrofes. ${ }^{41}$ Los fluidos corporales como la saliva y el fluido crevicular gingival son 
utilizados para evaluar enfermedades sistémicas y realizar diagnósticos clínicos, así mismo existen estudios en los que se reporta que la saliva y el fluido crevicular gingival son de utilidad para realizar el diagnóstico de la enfermedad periodontal debido a que se han identificado diversos marcadores que se podrían utilizar de manera rutinaria en la clínica para poder evaluar la progresión de esta enfermedad. Uno de los marcadores identificado es la Lactato Deshidrogenasa (LDH) enzima que normalmente se asocia al citoplasma de las células y sus valores se incrementan cuando existe daño en la membrana de las células durante la respuesta inflamatoria. ${ }^{42}$

\section{La saliva y el envejecimiento}

La sequedad de la boca (xerostomía) es una queja clínica común en los ancianos. Numerosos estudios han investigado el efecto de la edad sobre la secreción de las glándulas salivales. Algunos de los cambios más significativos que ocurren en los adultos mayores, ocurren en la mucosa, la función de la musculatura, la articulación temporomandibular, disgeusia, función salival, y sistema nervioso; la mucosa puede aparecer seca, atrófica, dolorosa y/o sensible. ${ }^{8,43}$ García y colaboradores indicaron en su estudio que la cantidad y la calidad de saliva correspondía con la consistencia fluida y que puede estar asociado con la disminución de la secreción de las glándulas salivales en la vejez, debido a un mecanismo de envejecimiento celular normal en el organismo, lo que puede ser resultado directo de la sustitución del tejido parenquimatoso o funcional por tejido fibroso, estos cambios a escala microscópica son más evidentes en la glándula parótida y salivales menores y pueden afectar la calidad del flujo salival. ${ }^{43}$

La cantidad de saliva se ve disminuida en el adulto mayor por situaciones comunes tales como: la acción de ciertos agentes farmacológicos, enfermedades sistémicas, intervenciones quirúrgicas, etapas normales de envejecimiento, la sequedad es una queja común entre los ancianos. En relación con la calidad, estudios plantean que la saliva se torna pegajosa y filamentosa y que tanto la calidad como la tasa de flujo salival están influenciadas por la edad. Lo anterior se hace más claro con estudios que describen que el sistema nervioso autónomo es responsable del control fisiológico de las glándulas salivales y que la estimulación parasimpática produce una vasodilatación que produce una secreción abundante y fluida, mientras que la estimulación simpática aumenta la secreción pero es de menor intensidad, la saliva es más viscosa y rica en mucina. Existen estudios que destacan que la disminución en el sentido del gusto se debe a la disminución en el número de papilas gustativas, así como, reducción de la salivación, lo que lleva a perder el gusto por las comidas y a estados de desnutrición y deficiencias de minerales entre otras. ${ }^{43}{ }^{44}$ Sivakumar en su estudio demostró que las características salivales en niños eran diferentes a las de los adultos, debido a la mayor carga proteica en infantes comparada con la población adulta, lo que demuestra que la concentración de proteínas disminuye a medida que avanza la edad. ${ }^{45}$ De allí que el conocer las características del envejecimiento en la fisiología y la patología de la cavidad bucal resulte de alto interés, dado que la saliva ha demostrado un rol protector frente a la caries y otras patologías orales. ${ }^{15}$

\section{Paramétros de evaluación salival}

Mientras que la composición de la saliva es compleja, sus propiedades respecto a protección de los tejidos duros y blandos orales, pueden ser evaluados en la consulta odontológica tradicional. Un método sistemático ampliamente utilizado para evaluar los parámetros salivales, es una secuencia que examina las propiedades físicas y químicas de la saliva relacionados con el estado bucal. ${ }^{2}$

\subsection{Flujo salival}

Entre las pruebas utilizadas para evaluar la actividad de caries dental y que están relacionadas directamente con la saliva se encuentra la determinación de la tasa de flujo. ${ }^{44,46}$ Las variaciones de la tasa de flujo influyen en muchos de los componentes químicos y propiedades de la saliva, entre las que se encuentran la de mantener y proteger las estructuras de la cavidad bucal debido a que contribuye a la remoción de los residuos alimentarios de los dientes; además, coadyuva con iones minerales y componentes inorgánicos al esmalte de los dientes y contiene buffers que ayudan a la neutralización de los ácidos que se forman en la placa. Algunos estudios reportan diversos aspectos relacionados con el funcionamiento de las glándulas salivales, donde citan que el flujo salival no estimulado es de $0,3 \mathrm{~mL} /$ $\mathrm{min}$ a $0,4 \mathrm{~mL} / \mathrm{min}$; cuando existen valores menores de $0,15 \mathrm{~mL} / \mathrm{min}$ es anormal. El flujo salival estimulado por la masticación es de 1,0 a $2,0 \mathrm{~mL} / \mathrm{min}$, si existen valores menores de $0,5 \mathrm{~mL} / \mathrm{min}$ a $4 \mathrm{~mL} / \mathrm{min}$ se considera también anormal. ${ }^{46,47}$

- Hiposalivación: la disminución de la función secretora de las glándulas salivales puede ser producto de enfermedades autoinmunes, desórdenes hormonales, neurológicos, hereditarios, infecciones, enfermedades locales de la glándula como la sialitiasis (cálculos en el conducto excretor de la glándula), sialoadenitis o carcinomas. Se ha observado que el riesgo de hipofunción salival aumenta con el incremento del número de fármacos ingeridos. ${ }^{48}$ se ha establecido que, en reposo, 
las glándulas salivales tienen una producción de aproximadamente $0,3 \mathrm{~mL} / \mathrm{min}$, pero éste aumenta a $3 \mathrm{~mL} / \mathrm{min}$ cuando la salivación es estimulada. En individuos sanos, la producción salival diaria se estima entre 500 y $600 \mathrm{~mL}^{49} \mathrm{El}$ efecto de esta condición es el aumento del riesgo de caries, en cuanto a su nivel de actividad y el grado de progresión. Igualmente, se observa un aumento en las infecciones de la mucosa oral. ${ }^{18}$

- Xerostomía: existe gran controversia en la definición de xerostomía e hiposalivación, la xerostomía se define como el síntoma subjetivo o sensación de boca seca, la hiposalivación es la definición objetiva de la reducción de la tasa de flujo salival, sin embargo, tanto en libros como artículos aún se hace referencia como xerostomía a los casos de boca seca. Esta disminución o ausencia de saliva puede causar una significante morbilidad y una reducción de la calidad de vida en los pacientes. Este síntoma afecta a los adultos entre 14 y 40\%. El temprano diagnóstico de la xerostomía y su manejo adecuado pueden prevenir lesiones cariosas múltiples y mejorar la calidad de vida. La saliva artificial resulta indispensable para miles de pacientes que sufren de resequedad bucal. ${ }^{44,50-52}$

- Hipersalivación (sialorrea): la sialorrea es un síntoma debido a un aumento del flujo de saliva. El diagnóstico y tratamiento de un paciente con hipersalivación se logra tras una serie de deducciones basadas en un intento serio y juicioso de explicar cada dato de la historia clínica. Desafortunadamente son escasos los estudios epidemiológicos de esta sintomatología, por lo que existe dificultad a la hora de encontrar series significativas. La sialorrea es un síntoma potencialmente incapacitante en muchos pacientes afectados por diversas enfermedades neurológicas crónicas. ${ }^{53,54}$

\section{Saliva como un fluido de diagnóstico}

La saliva es un fluido ideal para el diagnóstico de una variedad de condiciones, puesto que puede ser recogida fácilmente y no invasivamente. La gama de analitos incluye: microorganismos, tales como Streptococo mutans; marcadores de destrucción periodontal; virus, tales como hepatitis C; anticuerpos a los virus, como VIH; sustancias de grupos sanguíneos; drogas terapéuticas; alcohol y drogas ilícitas; hormonas esteroides, tales como cortisol, estrógeno, progesterona, testosterona y aldosterona; metales pesados, tales como mercurio, bismuto y plomo. La concentración de saliva relativamente baja en proteína asegura que las drogas y hormonas, normalmente unidas a las proteínas portadoras en el plasma, estén presentes en la forma no unida. En la saliva se pueden encontrar varias hor- monas lípido-solubles, en cantidades proporcionales a sus concentraciones en el plasma. El análisis de saliva permite monitorear con regularidad los niveles sistemáticos de estas hormonas. Desde el punto de vista de las ciencias forenses, existen diversos componentes de la saliva que son analitos importantes. Las sustancias del grupo de sangre $A B O$ se encuentran en la saliva del $80 \%$ de la población, y son conocidas como "secretoras"; esta característica es considerada clave invalorable de identificación forense. ${ }^{2}$

Recientemente, la combinación de las biotecnologías emergentes y diagnósticos salivales ha ampliado la gama de diagnóstico basado en la saliva de la cavidad oral a todo el sistema fisiológico. Un gran número de analitos médicamente valiosos en la saliva se dio a conocer poco a poco y representan biomarcadores para diferentes enfermedades incluyendo el cáncer. Estos avances han ampliado el enfoque de diagnóstico salival de la cavidad oral a todo el sistema fisiológico, y por lo tanto, el punto hacia un futuro prometedor para el diagnóstico en la saliva y aplicaciones en medicina, incluidas las decisiones clínicas y pronósticos de tratamiento. ${ }^{55}$

\section{BIBLIOGRAFÍA}

1. Llena-Puy C. The role of saliva in maintaining oral health and as an aid to diagnosis. Med Oral Patol Oral Cir Bucal 2006; 11: 449 - 455.

2. Walsh I. Aspectos clínicos de biología salival para el clínico dental. J Minim Interv Dent 2008; 1 (1): 5 -23.

3. Hernández AA, Gutiérrez MA, Agudelo D. Estado dental y necesidad de tratamiento en adultos mayores institucionalizados de Floridablanca, Santander [Trabajo de Grado]. Bucaramanga: Universidad Santo Tomás; 2011.

4. Bretas I, Rocha M, Vieira M, Rodrigues A. Fluxo salivar e capacidade tamponante da saliva como indicadores de susceptibilidade à doença cárie. Pesq Bras Odontoped Clin Integr, João Pessoa 2008; 8 (3): 289 - 293.

5. Tenovuo JO. Salivary parameters of relevance for asses sing caries activity in individuals and populations. Community Dent Oral Epidemiol 1997; 25: 82 - 86.

6. Kaufman E, Lamster B, The Diagnostic Applications of Saliva A Review, Crit Rev Oral Biol Med 2002; 13 (2): 197 - 212.

7. Téllez M. pH salival y su capacidad amortiguadora como factor de riesgo de caries en niños de la escuela primaria federal "Ignacio Ramírez" [Trabajo de grado]. Veracruz: Universidad Veracruzana; 2011. URL dispoonible en: http:// cdigital.uv.mx/bitstream/123456789/30932/1/TellezLicona.pdf

8. Dodds WJ, Johnson DA, Yeh CK. Health benefits of saliva: a review. J Dent 2005; 33 (3): 223 - 233.

9. Loyo K, Balda R, González O, Solórzano A, González M. Actividad cariogenica y su relación con el flujo salival y la capacidad amortiguadora de la saliva. Acta Odontol Venez 1999; 37 (3): $10-17$. 
10. Fasoli LC. El epitelio de las glándulas salivales. Saliva: Composición y secreción. Universidad Nacional de Cuyo, Facultad de Odontología ciclo 2010. URL disponible en: http://www.fodonto.uncu.edu.ar/upload/ salivasecrecion ycomposicion.pdf

11. Edgar WM. Saliva: it's secretion, composition and functions. Br Dent J 1992; 172: 305.

12. Lagerlöf F, Oliveby A. Caries-protective factors in saliva. Adv Dent Res 1994; 8 (2): 229 - 238.

13. Jiménez G, Solís H, Domínguez A, Benítez G. Alteraciones del ciclo circadiano en las enfermedades psiquiátricas: papel sincronizador de la melatonina en el ciclo sueñovigilia y la polaridad neuronal. Salud Mental 2011; 34:167 $-173$.

14. Chávez H. Saliva un Enfoque Integrativo. Editorial Dirección de Fomento Editorial. Universidad Autónoma de Puebla: Puebla; 2008.

15. Van Nieuw Amerongen A, Bolscher JG, Veerman EC. Salivary proteins: protective and diagnostic value in cariology. Caries Res 2004; 38: 247 - 253.

16. Castro RJ, Guzmán G, Giacaman RA. Comparación de la concentración total de proteínas salivales de adultos y adultos mayores Rev Clin Periodoncia Implantol Rehabil Oral 2012; 5 (1): 25 - 28.

17. Zárate NA, Leyva ER, Martínez FF. Determinación de pH y proteínas totales en saliva en pacientes con y sin aparatología ortodóncica fija (estudio piloto). Revista Odontológica Mexicana 2004; 8 (3): 59 - 63.

18. Núñez DP, García L. Biochemistry of dental caries. Revista Habanera de Ciencias Médicas 2010; 9 (2): 156-166.

19. Martínez I, Morales JM. Ingestión de azúcares en niños menores de un año. Revista Médica Electrónica 2008; 28 (1): $113-116$.

20. Tschoppe P, Pischon N, Kielbassa A. Etiologic factors of hyposalivation and consequences for oral health. RCOE 2010; 41 (4): 321 - 333.

21. Bárbara E. García T, Delfin O, Saldaña A. Principales proteínas salivales: estructura, función y mecanismos de acción. Revista Habanera de Ciencias Médicas 2012; 11 (4): 450- 456.

22. Busch 1, Borda E. Mucinas salivales: estructura química, mecanismos de liberación y participación en la defensa no inmunológica de la cavidad bucal. Rev Fac Odonto (B. Aires) 2009; 24: 56 - 57.

23. Echeverri MT. La saliva: componentes función y patología. Revista de Estomatología 1995; 4 (2): 55 - 63.

24. De Almeida P del V, Grégio AM, Machado MA, de Lima AA, Azevedo LR. Saliva composition and functions: a comprehensive review. J Contemp Dent Pract 2008; 9 (3): 72 - 80. , digital www.jcdp.com marzo 2008;9(3) (consultado 7 de junio de 2013)

25. Llena-Puy MC, Almerich-Silla JM, Forner-Navarro 1. Determinación de ácido láctico en el dorso de la lengua. Su relación con la presencia de caries activa. RCOE 2004; 9 (3): 303 - 308.

26. Acosta G, Frías S, Reyes MR, Ahuatzin I, Pacheco A, Gertrudiz N, Vázquez A, Urea salival y telehemodiálisis. Rev Hosp Jua Mex 2007; 74 (2): 66 - 68.

27. Cosio DJ, Ortega AO, Vaillard E. Determinación del pH salival antes, durante y después del consumo de caramelos en niños y niñas de 3, 4 y 5 años de edad. Oral 2010; 11 (35): $642-645$
28. Duque J, Pérez JA, Hidalgo-Gato I. Caries dental y ecología bucal, aspectos importantes a considerar. Facultad de Ciencias Médicas de Matanzas "Juan Guiteras Gener" [en línea]. URL disponible en: http://www.bvs.sld.cu/revistas/ est/vol43_1_06/est07106.htm.

29. Carrillo C. Desmineralización y remineralización El proceso en balance y la caries dental. Revista ADM 2010; 67 (1): $30-32$.

30. Figueroa PF. Efecto de uso de productos dentales que contienen xilitol durante ocho semanas en el número de Unidades Formadoras de Colonias de Streptococcus del grupo mutans en saliva de niños y niñas del patronato municipal San Pedro de Ribamba [Trabajo de Grado]. Quito: Universidad San Francisco de Quito; 2008. URL disponible en: http://repositorio.usfq.edu.ec/ bitstream/23000/514/1/86591.pdf

31. Gati D,Vieira AR. Elderly at greater risk for root caries: a look at the multifactorial risks with emphasis on genetics susceptibility. Int J Dent 2011: 1 - 6.

32. Rodríguez LO, Guiardirú R, Arte M, Jiménez V, Echevarría $S$, Calderón A. Factores de riesgo y prevención de caries en la edad temprana ( 0 a 5 años) en escolares y en adolescentes [en línea] URL disponible en: http://www.medellin. gov.co/irj/go/km/docs/wpccontent/Sites/Subportal\%20 del\%20Ciudadano/Salud/Secciones/Programas\%20y\%20 Proyectos/Documentos/2013/APS/Factores\%20de\%20 riesgo $\% 20$ y $\% 20$ prevención $\% 20$ de $\% 20$ caries $\% 20$ en $\% 20$ la\%20edad\%20temprana.pdf

33. Gésime JM, Acevedo AM, Lalaguna F. Las mucinas salivales y sus implicaciones en la reología de la saliva humana y los sustitutos salivales. Acta Odontol Venez [en línea] 2009; 47 (2): 446 - 452. URL disponible en: http:// www.scielo.org.ve/scielo.php?script =sci_arttext\&pid $=$ S0001-63652009000200 024 \&lng=es.

34. Water,am HA, Blom C, Holterman HJ, 's-Gravenmade EJ, Mellema J. Rheological properties of human saliva. Arch Oral Biol 1988; 33 (8): 589 - 596.

35. Méndez-Sánchez AF, Pérez-Trejo L, Paniagua Mercado AM. Determinación de la viscosidad de fluidos newtonianos y no newtonianos. Lat Am J Phys Educ 2010; 4 (1): 237 - 245.

36. Huertas C, Hueso F. Medida de la viscosidad y densidad de dos líquidos [en línea]. URL disponible en: http://mural.uv.es/ferhue/10/Viscosidad liquidos FHG.pdf

37. Zerón A. Acid erosion tribology in dentistry new dental wear. Revista AdM 2009; 65 (5): 12 - 16.

38. Bhumika B, Kumar A, Pravin Maru V. Role of saliva in dental practice - a review. J Dent Sci 2013;1 (1): 1 - 6 .

39. Universidad Pablo de Olavide de Sevilla. Medida de viscosidades y densidades [en línea]. URL disponible en: http:// www.upo.es/depa/webdex/ quimfis/docencia/basesFQ/ Pract/cuatroycinco.pdf

40. Castrillón LE, Palma A, Macín S. Papel de la lactoferrina en enfermedades periodontales. Revista Odontológica Mexicana 2011;15 (4): 231 - 238.

41. Todorovic T, Dozic I, Vicente-Barrero M, Ljuskovic B, Pejovic J, Marjanovic M, Knezevic M. Enzimas salivales y enfermedad periodontal. Med Oral Patol Oral Cir Bucal 2006; 11:115 - 119.

42. Leyva ER, Esquivel C, Marín G, Neblina M, Olivares S. Actividad de la lactato deshidrogenasa en fluido crevicular gingival y saliva en fumadores con periodontitis crónica. Av Periodon Implantol 2000; 21 (1): 21 - 26.

43. García CM, Sánchez H, Martínez AO. Cambios morfológicos que influyen en el tratamiento protésico del paciente 
geriátrico. Ministerio de Salud Pública, Instituto Superior De Ciencias Médicas Camaguey, URL disponible en: http:// www.sld.cu/galerias/pdf/uvs/saludbucal/morfprotesis.pdf

44. Rodríguez EH, Sacsaquispe SJ. Tasa de flujo salival y nivel de confort al emplear saliva artificial y caramelos de menta sin azúcar en adultos mayores con xerostomía. Rev Estomatol Herediana 2006; 16 (2): 103-109.

45. Sivakumar T, Hand AR, Mednieks M. Secretory proteins in the saliva of children. J Oral Sci 2009; 51 (4): 573 - 580.

46. Ortega ME, Calzado M, Pérez M. Evaluación del flujo y viscosidad salival y su relación con el índice de caries. Medisan 1998; 2 (2): 33 - 39.

47. Morales R, Aldape Barrios B. Flujo salival y prevalencia de xerostomía en pacientes geriátricos, Revista ADM 2012; 70 (1): $25-29$.

48. Aranguiz V. Importancia de la saliva en la salud bucal. Dosis Capacitación [en línea]. URL disponible en: http:// revistadosis.com.ar/pdf/ct4.pdf

49. Chapa AG, Garza SB, Garza EM, Martínez SG. Hiposalivación y xerostomía; diagnóstico, modalidades de tratamiento en la actualidad: aplicación de neuroelectroestimulación- Revista Mexicana De Periodontología 2012; 3 (1): 38 - 46.

50. Ibáñez Mancera N, López García CJ, Piña B. Frecuencia de hiposalivación (xerostomía), Revista ADM 2009; 65 (5): $56-60$.

51. Antoranz, A, Casado I, Corral, C, Cerero R, López, P. Pacientes con xerostomía: un reto terapéutico para el odontoestomatólogo. Cient Dent 2011; 8 (3): 213 - 217.

52. Chimenos E, Marques MS. Boca ardiente y saliva. Medicina Oral 2002; 7 (4): $244-248$.

53. Aguilar F. Tratamiento de sialorrea en enfermedades neurológicas más frecuentes del adulto. Plast \& Rest Neurol 2006; 5 (2): $123-128$.

54. López MP, et al. Estrategias actuales para diagnóstico y tratamiento de pacientes con sialorrea. Rev Clin Esp 2002; 202 (8): $441-443$.

55. Spielmann W. Saliva: diagnostics and therapeutic perspectives. Oral Dis 2011; 17 (4): 345 - 354

Correos electrónicos de los autores:

Anne Alejandra Hernández Castañeda: anne.usta@hotmail.com Gloria Cristina Aránzazu Moya: aranzazugloria@yahoo.es
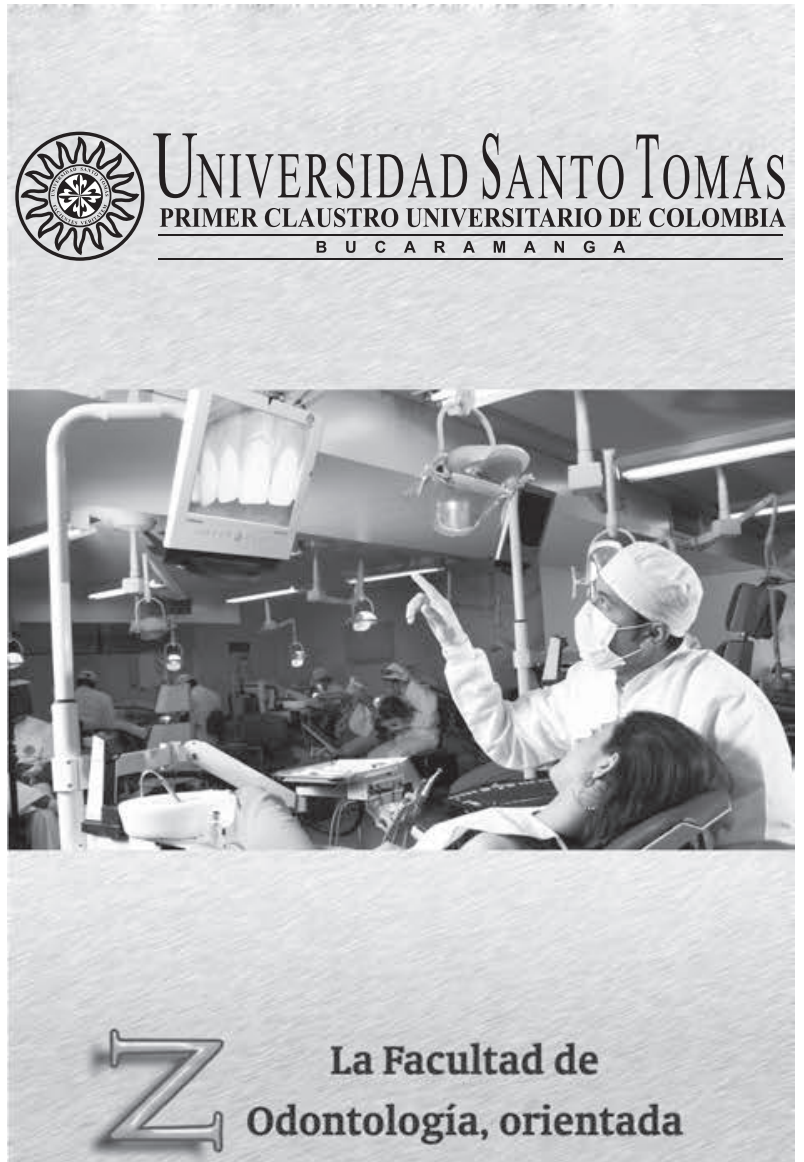

La Facultad de

Odontología, orientada

por el pensamiento de

Santo Tomás, pretende

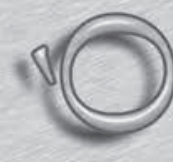

formar Odontólogos

integrales $\mathrm{y} / \mathrm{o}$

especialistas a través de

parámetros

humanisticos, éticos, científicos,

biotecnológicos,

investigativos y

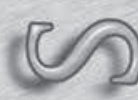

sociales, como recurso

humano capaz de

intervenir con éxito en

el proceso dinámico de

la salud y la

enfermedad, en el

individuo, la familia y la

comunidad. 